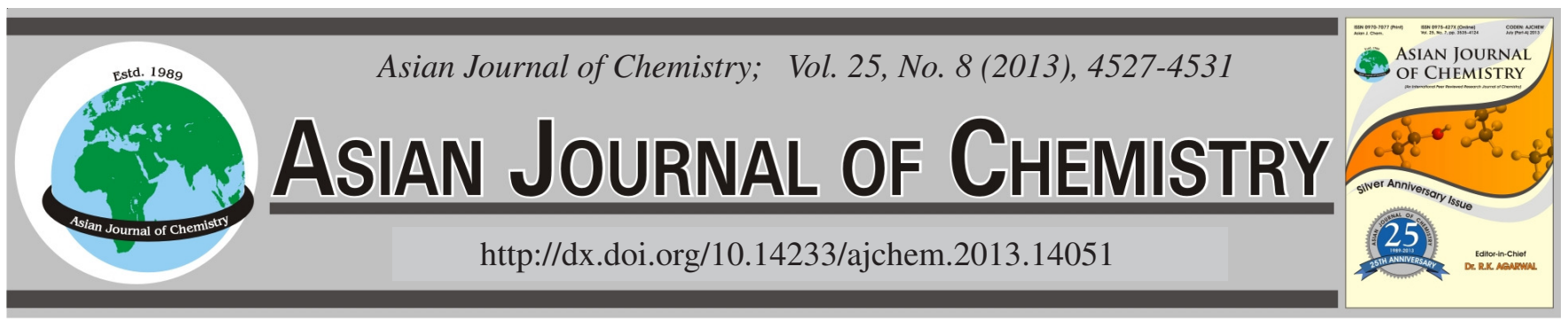

\title{
Conformational Analysis and Physical-Chemistry Property Relationship for 22-Membered Macrolides
}

\author{
Salah Belaidi* and Nadjib MelKemi
}

Department of Chemistry and Exact Science, Faculty of Science of Nature and Life, University of Biskra, BP 145, 07000, Biskra, Algeria

*Corresponding author: Tel:/Fax: +213 33 748687; E-mail: salah_belaidi@ hotmail.com; prof.belaidi@gmail.com

\begin{abstract}
Conformational analysis of 22 membered macrolactones has been carried out using molecular mechanics calculations and molecular dynamics. A high conformational flexibility of macrolactones was obtained and an important stereoselectivity was observed for the complexed macrolactones. For $22 \mathrm{~d}$ macrolactone, which was presented by a most favoured conformer with $20.1 \%$ without complex; it was populated with $36.2 \%$ in presence of $\mathrm{Fe}(\mathrm{CO})_{3}$. An additional study is performed of structure-property relationship for a series of 22-membered macrolides antibiotics.
\end{abstract}

Key Words: Macrolactone, Conformational analysis, Molecular mechanics, Molecular dynamics, Structure-property relationship.

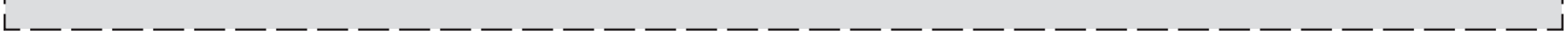

\section{INTRODUCTION}

Recently an increasing interest for the study of these molecules ${ }^{1,2}$ due to their biological importance of macrolides, presenting for the most an antibacterial activities and their medical use has swiped away.

Among these products which have a major importance, the macrocyclic antibiotics on account of their biological interest a large number of synthesis methods were elaborated ${ }^{3}$. Structure elucidation of a large number of obtained molecules shows the existence of two parts ${ }^{4}$. The first one is a macrocyclic system from 12 to 40 links with several asymmetric centers and lactone function and the second is a sugar part.

A literature survey revealed that a number of 22- or 24membered macrolides, such as macrolactins A-M, have previously been reported from a deep-sea bacterium ${ }^{5}$, marine Bacillus sp. PP 19-H3 ${ }^{6}$, marine Bacillus sp. So $26^{7}$ and from a culture broth of Actinomadura sp. ${ }^{8}$. Macrolatin A has been reported to show selective antibacterial activity and cytotoxicity against B16-F10 murine melanoma cancer cells ( $\left.\mathrm{IC}_{50}\right)$ $=3.5 \mu \mathrm{g} / \mathrm{mL}$ and antiviral activities against Herpes simplex type I and type II $\left(\mathrm{IC}_{50}\right)=5.0$ and $8.3 \mu \mathrm{g} / \mathrm{mL}$, respectively) and $\mathrm{HIV}^{5}$, as well as squalene synthase inhibitory activity ${ }^{9}$. Swinholide- $\mathrm{A}^{10}$, an antifungal compound isolated from a red sea sponge, was another 22-membered macrolide related to compounds 1-4; the dolabelides ${ }^{11}$.

Twenty two-membered macrolides from the sea hare Dolabella auricularia (Aplysiidae), are cytotoxic. Wortmannilactones A-D from fungus Talaromyces wortmannii ${ }^{12}$, exhibited in vitro cytotoxic activity against several human cancer cell lines with $\mathrm{IC}_{50}$ values ranging from 28.7 to $130.5 \mu \mathrm{M}$.

Still and Galynker ${ }^{13}$ have shown that conformational properties of middle and large size ( 8 to 14 atoms) might induce a diastereoselection phenomenon for the reactions carried out on these compounds. More precisely macrocycles which have a double bond $(\mathrm{C}=\mathrm{C}, \mathrm{C}=\mathrm{O})$ and substitutes correctly situated adopt privileged conformations.

Grée et al. ${ }^{14-17}$ have shown in some cases the possibility of a stereo-chemical control induced by tricarbonyliron. So, our objective is to verify if this notion can be extended for cycles with large size. In this paper we propose to study the 22 -membered $\alpha, \beta$-unsaturated macrocycle in a view to determine the most privileged conformations and the influence of $\mathrm{Fe}(\mathrm{CO})_{3}$ on conformational flexibility of these macrocycles.

Then, our object is to search the favoured conformation, on the basis of energy and geometric considerations with statistical calculations using Boltzmann distribution ${ }^{18}$.

In this part of our work, we have undertaken a conformational study of 22 macrocycle (Fig. 1), symmetrical which we will design $22 \mathrm{~s}\left(\mathrm{n}_{1}=\mathrm{n}_{2}=7\right)$, dissymmetrical which we will design $22 \mathrm{~d}\left(\mathrm{n}_{1}=6, \mathrm{n}_{2}=8\right)$, which represent the core group for many macrolide antibiotics.

We will also try to evaluate the stereoselectivity of addition reactions carried out on functional groups appended to the tricarbonyliron moiety. Finally, we have studied some of QSAR proprieties of a series of 22-membered macrolides by HyperChem software. 


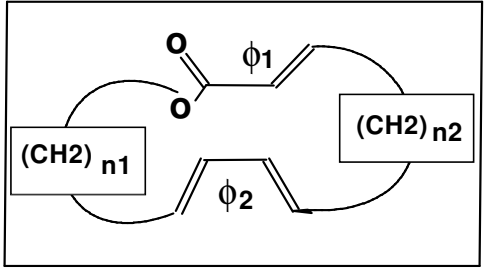

Fig. 1. $\alpha, \beta$-unsaturated macrolactone

\section{EXPERIMENTAL}

In this study, the main method of calculation is molecular mechanics. This is considered as the most appropriate method for larger molecules ${ }^{19}$. Programs are based on Allinger force field $^{20}$. This method for structure determination includes a quantum mechanical (VESCF) $\pi$-system calculation in the iterative sequence. They use Metropolis algorithm ${ }^{21}$.

We also used the molecular dynamics (HyperChem) for the conformational research, with following options: $1000 \mathrm{~K}$, in vacuo, step size: $0.001 \mathrm{ps}$ and relaxation time: $0.1 \mathrm{ps}$. These calculations were carried out with two software packages: HyperChem $(8.03)^{22}$ and Chem 3D $(8.0)^{23}$.

\section{RESULTS AND DISCUSSION}

Conformational analysis of 22-membered macrolactones: The most stable structures can be characterized by three structural characters: the diene group, the $\alpha, \beta$-unsaturated ester group and the two saturated chains. Thus, we have obtained eight types of conformations which are present in the majority of cases in a $5 \mathrm{kcal} / \mathrm{mol}$ energy range above the global minimum. The conformation types are classed from 1 to $8^{24-28}$.

For types $(2,4,6,8)$, the two planes of two conformational sites; diene and $\alpha, \beta$-unsaturated ester group were pseudoparallels. But for types $(1,3,5,7)$, the two planes of the two sites are pseudo-antiparallel (Fig. 2).

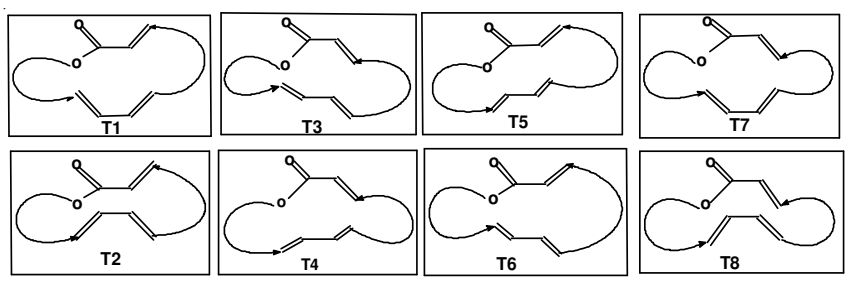

Fig. 2. Main conformational types

It is also noted that for two conformations which we distinguish by the arrangement between the two sites, the dipole moment values are higher for pseudo-parallel arrangement and lower in the opposite case (for the macrocycle $22 \mathrm{~s}$, $\mu(\mathrm{T} 2)=2.29 \mathrm{D}$ and $\mu(\mathrm{T} 1)=1.97 \mathrm{D})$.

In $1 \mathrm{kcal} / \mathrm{mol}$ difference, the macrocycle $22 \mathrm{~d}$ is characterized by the first conformer type 3 , which is the most favoured with $20.1 \%$ rate followed by a type 4 with $15.6 \%$. Then, the macrocycle $22 \mathrm{~s}$ is presented preferably in the type $\mathrm{T} 4(17.9 \%)$ and type $\mathrm{T} 3(17.5 \%)$.

The percentages of other conformation types are listed in Table-1. The conformer populations of macrocycle $22 \mathrm{~d}$ are lightly greater than these of macrocycle $22 \mathrm{~s}$. For the most favoured conformer geometry, the $\alpha, \beta$-unsaturated ester group has s-trans conformation with an angle $\phi_{1}$ : O23-C2-C3-C4 = $179.6^{\circ}$ for macrocycle $22 \mathrm{~d}$ and $\phi_{1}$ : O23-C2-C3-C4 $=170.3^{\circ}$ for cycle $22 \mathrm{~s}$.

TABLE-1

ENERGETIC DIFFERENCE AND BOLTZMANN POPULATION FOR DIFFERENT CONFORMATIONALS TYPES

\begin{tabular}{lccc|ccc}
\hline \multirow{2}{*}{ Macrolactone } & \multicolumn{3}{c|}{$\begin{array}{c}\text { 22 symmetric } \\
\left(\mathrm{n}_{1}=\mathrm{n}_{2}=7\right)\end{array}$} & \multicolumn{3}{c}{$\begin{array}{c}\text { 22 dissymmetric } \\
\left(\mathrm{n}_{1}=6, \mathrm{n}_{2}=8\right)\end{array}$} \\
\cline { 2 - 7 } & Type & $\Delta \mathrm{E}$ & $\%$ & Type & $\Delta \mathrm{E}$ & $\%$ \\
\hline To $1 \mathrm{kcal} / \mathrm{mol}$ & 4 & 0.00 & 17.9 & 3 & 0.00 & 20.1 \\
& 3 & 0.08 & 17.5 & & & \\
To $2 \mathrm{kcal} / \mathrm{mol}$ & 5 & 0.36 & 16.4 & & & \\
& 6 & 1.47 & 12.5 & 4 & 1.06 & 15.6 \\
& & & & 5 & 1.49 & 14.0 \\
Sup to 2 kcal/mol & 7 & 2.47 & 09.8 & 6 & 2.68 & 10.5 \\
& 8 & 2.69 & 09.3 & 7 & 2.80 & 10.2 \\
& 1 & 2.75 & 09.2 & 2 & 2.93 & 09.9 \\
& 2 & 3.55 & 07.5 & 1 & 4.43 & 06.9
\end{tabular}

$\Delta \mathrm{E}$ : Energetic difference to the absolute minimum, \%: Boltzmann population

The diene group has s-trans conformation with a torsion angle $\phi_{2}$ : $\mathrm{C} 13-\mathrm{C} 14-\mathrm{C} 15-\mathrm{C} 16=172.4^{\circ}$ for $22 \mathrm{~d}$ and $\phi_{2}$ : $\mathrm{C} 12-$ $\mathrm{C} 13-\mathrm{C} 14-\mathrm{C} 15=177.2^{\circ}$ for $22 \mathrm{~s}$. The two systems ester and diene are parallel between themselves. These macrocycles have high conformational flexibility.

However, mobility of dissymmetric macrocycles is lightly less important than that of symmetric macrocycles. They present many privileged conformations that do not a priori foresee a diastereoselection for envisaged reactions. This is in agreement with Still's works ${ }^{13}$, on macrocycle ${ }^{17}$, which yields many different conformations ${ }^{29}$ (Fig. 3)
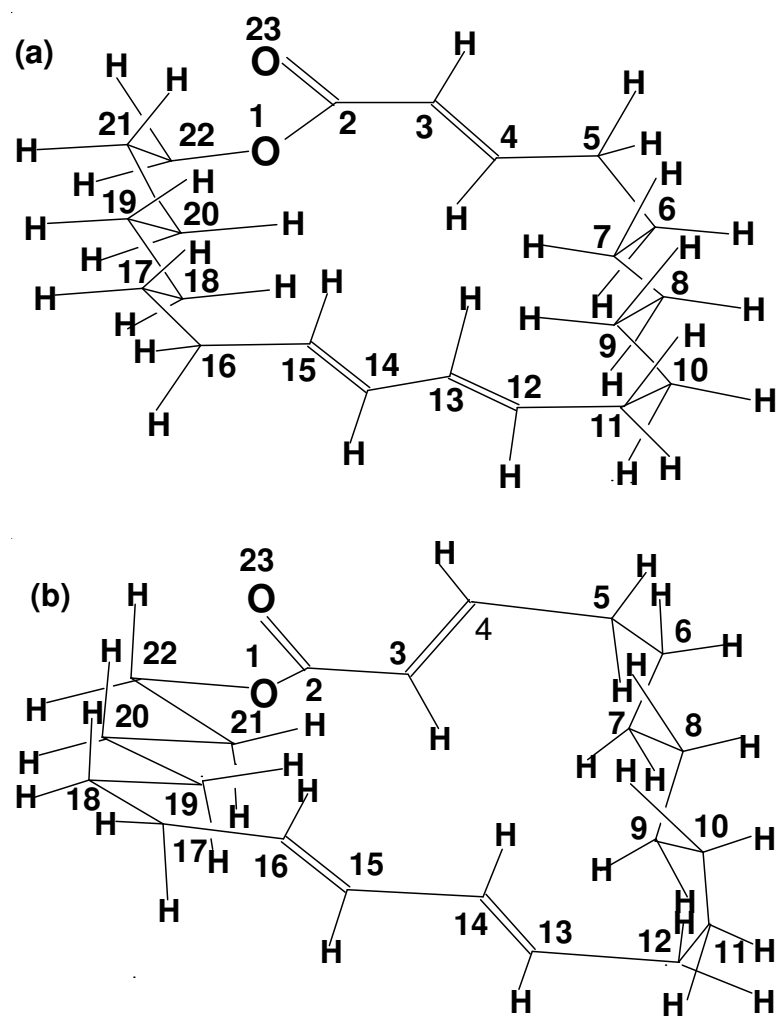

Fig. 3. Most favoured conformers of macrocycles: 22s (a) and 22d (b) 
Introduction of tricarbonyliron moiety: We have studied also the exerted effect by tricarbonyliron on conformational flexibility of these macrocycles. It is noted that organometallic complex can intervene by a high steric hindrance and also introducing an important rigidification of skeleton. The results of conformational analysis of two complexed macrocycles 22 show that tricarbonyl iron has a considerable influence on cycles, because the number of possible conformations was reduced to four types ${ }^{26}$.

In $1 \mathrm{kcal} / \mathrm{mol}$ energetic difference, the complexed macrocycle $22 \mathrm{~s}$ shows three favoured conformations and only one favoured conformation for $22 \mathrm{~d}$.

The peopling rate of the most stable conformers was increased for complexed macrocycles compared with these without tricarbonyliron (Table-2).

TABLE-2

ENERGETIC DIFFERENCE AND BOLTZMANN POPULATION OF DIFFERENT CONFORMATIONAL TYPES OF COMPLEXED MACROCYCLES

\begin{tabular}{lcccccc}
\hline \multirow{2}{*}{ Macrolide } & \multicolumn{3}{c}{$\begin{array}{c}\text { 22 symmetric } \\
\left(\mathrm{n}_{1}=\mathrm{n}_{2}=7\right)\end{array}$} & \multicolumn{3}{c}{$\begin{array}{c}\text { 22 dissymmetric } \\
\left(\mathrm{n}_{1}=6, \mathrm{n}_{2}=8\right)\end{array}$} \\
\cline { 2 - 7 } & Type & $\Delta \mathrm{E}$ & $\%$ & Type & $\Delta \mathrm{E}$ & $\%$ \\
\hline To 1 & 1 & 0.00 & 28.1 & 8 & 0.00 & 36.2 \\
$\mathrm{kcal} / \mathrm{mol}$ & 7 & 0.16 & 27.0 & & & \\
& 8 & 0.63 & 24.1 & & & \\
Sup to 1 & 2 & 1.23 & 20.8 & 7 & 1.96 & 22.5 \\
kcal/mol & & & & 2 & 2.04 & 22.0 \\
& & & & 1 & 2.59 & 19.3 \\
\hline
\end{tabular}

For macrocycle $22 \mathrm{~d}$, which was presented by a preferred conformer with $20.1 \%$ without complex, it was populated with $36.2 \%$ in presence of $\mathrm{Fe}(\mathrm{CO})_{3}$.

We remark also that macrocycles $22 \mathrm{~s}$ and $22 \mathrm{~d}$ were presented, respectively, in T1 type with $28.1 \%$ and T8 type with $36.2 \%$ for the most favoured conformers. Dienic system was fixed in s-cis conformation for all preferential conformations. The dihedral angle value of dienic system was comprized between 0.69 and $2.74^{\circ}$ for $22 \mathrm{~s}$ cycle and between 4.8 and $11.0^{\circ}$ for $22 \mathrm{~d}$ cycle. The lower deviations of registered dihedral angles compared with normal values were imposed essentially by a cyclic chain.

The presence of tricarbonyliron motif imposes a minimum steric modification and introduces an asymmetric element. So, this creates a favourable environment to discrimination between two faces of macrocycles increasing thus a peripheral attack proportion (Fig. 4). This reasoning was found again in methyl acetates with fluorine containing auxiliaries where intramolecular interaction Li-F creates a steric hindrance around one of two faces causing a diastereofacial selectivity of 94.6: $5.4^{30}$. The lactone function and complexed diene were practically perpendicular at medium plane of the cycle. This is in agreement with Still's works ${ }^{13}$ that affirm that $\mathrm{CH}_{3} \mathrm{I}$ addition will be executed on the clear face by peripheral attack ${ }^{13}$. The study carried out by $\mathrm{Cox}$ and $\mathrm{Ley}^{31}$, on $\mathrm{Fe}(\mathrm{CO})_{3}$ complexes has shown that the presence of complex, which has an important steric effect, induced a diastereoselectivity in addition reactions (Fig. 4).

Study of structure physico-chemical property relationship for a series of 22-membered macrolides: We have studied six physico-chemical proprieties of series of four macrolides by HyperChem software, e.g., in Fig. 5, the favoured conformation in $3 \mathrm{D}$ of the compound 4 . We will continue this work in the future by a quantitative calculation. QSAR proprieties are van der Waals-surface-bounded molecular volume, the log of the octanol-water partition coefficient $(\log$ P), polarizability and solvent-accessible surface-bounded molecular volume and molecular mass (M). Calculation of $\log \mathrm{P}$ is carried out using atomic parameters derived by Viswanadhan and coworkers ${ }^{32}$. Computation of molar refractivity was made via the same method as log P. Ghose and Crippen presented atomic contributions to the refractivity ${ }^{33}$.
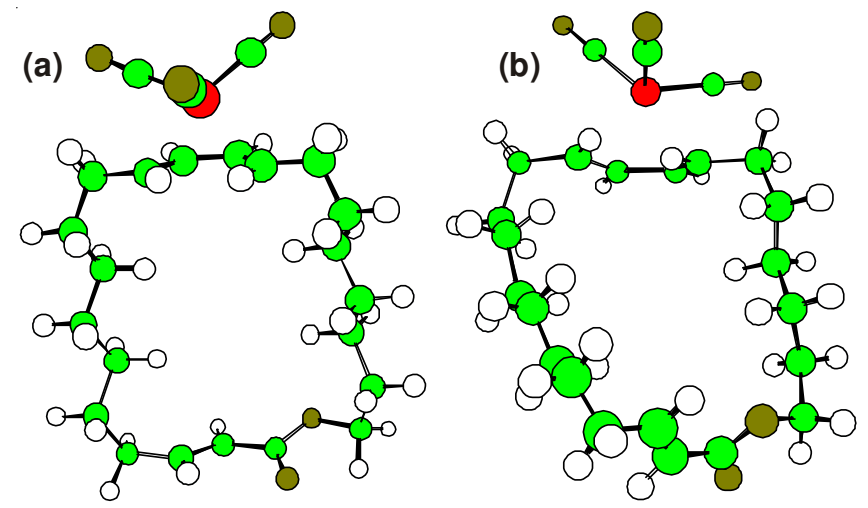

Fig. 4. Most favoured conformers of complexed macrocycles $22 \mathrm{~s}$ (a) $22 \mathrm{~d}$ (b) (Chem 3 D)

The solvent-accessible surface bounded molecular volume and van der Waals-surface-bounded molecular volume calculations are based on a grid method derived by Bodor et al. ${ }^{34}$, using the atomic radii of Gavezotti ${ }^{35}$. The polarizability was estimated from an additivity scheme given by Miller ${ }^{36}$ with a precision on the calculation of $3 \%$, where different increments are associated with different atom types. The hydration energy is a key factor determining the stability of different molecular conformations in water solutions ${ }^{37}$. The calculation is based on exposed surface area as computed by the approximate method (above), weighted by atom type.

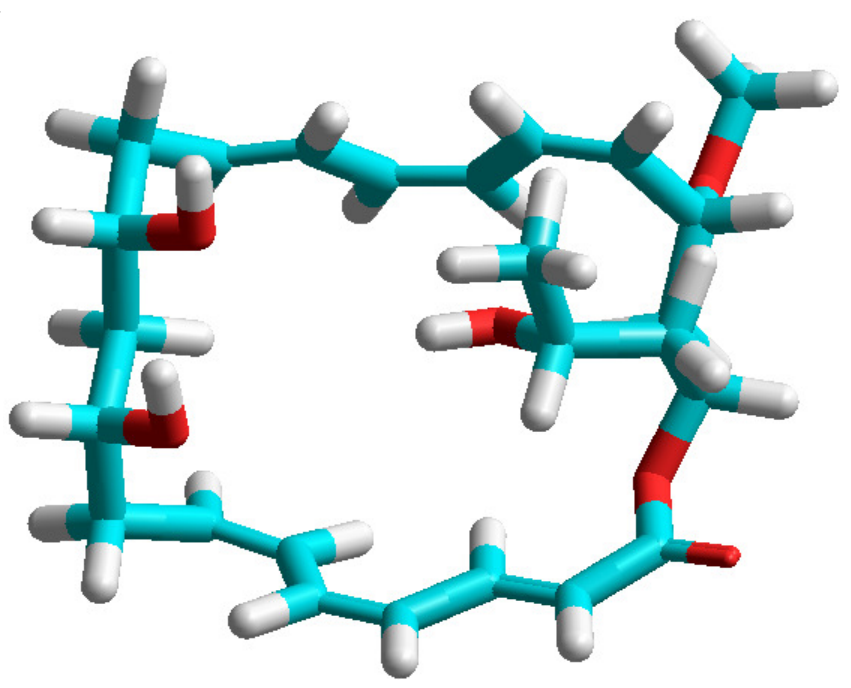

Fig. 5. 3D conformation of compound 4 (HyperChem) 
TABLE-3

QSAR PROPRIETIES FOR 22-MEMBERED MACROLIDES

\begin{tabular}{ccccccc}
\hline Macrolide & $\begin{array}{c}\text { Molecular volume } \\
\left(\AA^{3}\right)\end{array}$ & $\begin{array}{c}\text { Molecular surface } \\
\left(\AA^{2}\right)\end{array}$ & $\begin{array}{c}\text { Molecular mass } \\
(\text { uma })\end{array}$ & $\begin{array}{c}\text { Partition } \\
\text { coefficient }(\text { Log P) }\end{array}$ & $\begin{array}{c}\text { Hydratation energy } \\
(\mathrm{kcal} / \text { mol })\end{array}$ & $\begin{array}{c}\text { Polarizability } \\
\left(\AA^{3}\right)\end{array}$ \\
\hline 1 & 1139.59 & 601.19 & 418.53 & 2.48 & -10.30 & 46.16 \\
2 & 1183.94 & 620.84 & 432.56 & 2.75 & -9.06 & 47.99 \\
3 & 1166.49 & 606.71 & 418.53 & 2.48 & -9.96 & 46.16 \\
4 & 1219.37 & 634.94 & 432.56 & 2.75 & -6.57 & 47.99 \\
\hline
\end{tabular}

Structural comparison of 22-membered macrolides: We chose a series of macrolide, some having a biological activity. This series of macrolides has been isolated from a fungus Talaromyces wortmannii ${ }^{12}$. Initially, we performed a structural comparison of this series (Fig. 6). These molecules have a weak conformational flexibility, with regard to the other macrocycles of macrolide type ${ }^{16,17}$. In a window of $2 \mathrm{kcal} / \mathrm{mol}(\mathrm{MM})$, only one favoured conformation is found, for each structure.

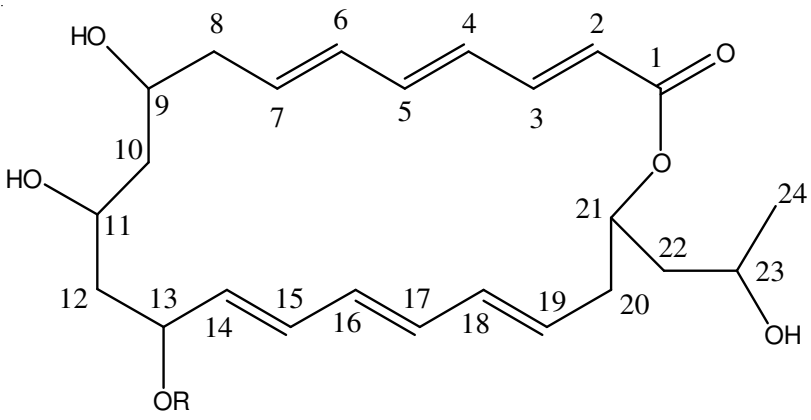

1: $\mathrm{R}=\mathrm{H}, 2: \mathrm{R}=\mathrm{CH}_{3}$

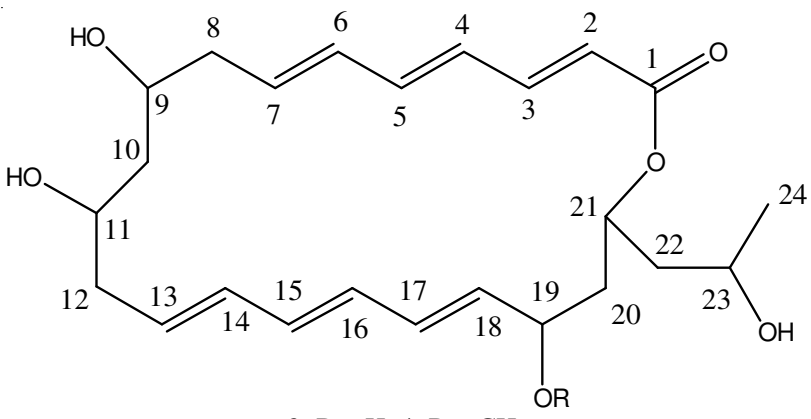

3: $\mathrm{R}=\mathrm{H}, 4: \mathrm{R}=\mathrm{CH}_{3}$

Fig. 6. Structure of 1-4 macrolide derivatives

QSAR proprieties for 22-membered macrolides: Lipophilicity is a property that has a major effect on solubility, absorption, distribution, metabolism and excretion properties as well as pharmacological activity. Lipophilicity has been studied and applied as an important drug property for decades. It can be quickly measured or calculated. Lipophilicity has been correlated to many other properties, such as bioavailability, storage in tissues, permeability, volume of distribution, toxicity, plasma protein binding and enzyme receptor binding ${ }^{38}$.

The values of polarizability are generally proportional to the values of surfaces and of volumes. The macrolide $\mathbf{1}$ and $\mathbf{3}$ have the same value of the polarizability $\left(46.16 \AA^{3}\right)$ superior to values of macrolides $\mathbf{2}$ and $\mathbf{4}$, which have the same value (47.99 $\AA^{3}$ ) (Table-3). The order of polarizability is the same one for volume and surface. This is also explained by the relation between polarizability and volume, for the relativity non polar molecules. They are directly linked, for the centers of gravity of negative and positive charges in the absence of external fields to coincide and the dipole moment of the molecule is zero. The polarizability of the molecule depends only on its volume while the thermal agitation of the nonpolar molecules does not depend solely on volume, but also depends on other factors such as the temperature, because of the presence of the permanent dipole ${ }^{39}$.

The surface and the volume of distribution of these molecules are definitely higher than that of more polar molecules like the lipopeptides or $\beta$-lactams. For example, Deleu et al. ${ }^{41}$ used TAMMO software ${ }^{40}$ on the surfactins C13, C14 and C15 having cores similar to the macrolides. They ${ }^{41}$ found that their surfaces vary from 129 to $157 \AA^{2}$, contrarily for these macrolides, surfaces vary from 601 to $635 \AA^{2}$. These macrolides has a great variation of distribution volume, in particular compound 4 and compound 2 which have respective volumes: 1219.37 and $1183.94 \AA^{3}$ (Table-3).

The hydration energy in the absolute value, most important is that of the compound $1(10.30 \mathrm{kcal} / \mathrm{mol})$ and the weakest is that of compound $4(6.57 \mathrm{kcal} / \mathrm{mol})$ (Table-3). Indeed in the biological environments the polar molecules are surrounded by water molecules. It is established hydrogen bonds between a water molecule and these molecules. The donor sites of proton interact with the oxygen atom of water and the acceptor sites of proton interact with the hydrogen atom.

The first correspond to the complex with the strongest hydrogen bond. These hydrated molecules are dehydrated at least partially before and at the time of their interaction. These interactions of weak energy, which we observe in particular between messengers and receivers, are generally reversible ${ }^{42}$.

Compound 1 has four donor sites of proton $(\mathrm{OH}$ in 9,11 , 13 and 23 position) and one acceptor site of proton $(\mathrm{C}=\mathrm{O})$. On the other hand the compound has three donor sites $(\mathrm{OH}$ in 9, 13 and 23 position) and two proton acceptor sites (carbonyl and methoxy groups). This can be explained by the steric effect between the methoxy group and the cycle of macrolide. This property supports the first compound, not only by fixing on the receiver, but in more activates it. It is thus about an agonist.

All $\log$ P (coefficient of division) of studied molecules have optimal values. For good oral bioavailability, the $\log \mathrm{P}$ must be greater than zero and less than $3(0<\log \mathrm{P}<3)$. For $\log \mathrm{P}$ too high, the drug has low solubility and a $\log \mathrm{P}$ too low; the drug has difficulty penetrating the lipid membranes ${ }^{38}$.

Macrolides $\mathbf{2}$ and $\mathbf{4}$ have a value that partition coefficient (2.75) compared to the two macrolides $\mathbf{1}$ and $\mathbf{3}$ (2.48). These molecules possess a good solubility. When the coefficient of division is rather low, it has as a consequence of a better gastric tolerance. The hydrophobicity of these molecules is of great importance in regard to the ease with which these substances 
can cross the plasma membrane, as well as with regard to interactions at the receptor.

\section{Conclusion}

It is concluded that the study that we have carried out shows the existence of high conformational mobility increasing in a majority of non complexed macrolides. The introduction tricarbonyliron in a skeleton permitted to fix the function diene in s-cis conformation. This has introduced an asymmetric element, an important steric effect increasing the peripheral attack proportion. The observed diastereoselectivity for complexed macrolides is a result of tricarbonyliron control effect. This factor constitutes a tool of the stereochemical remote control, which permits us to foresee a priori the phenomenon of the stereoselectivity for envisaged reactions. The compounds $\mathbf{1}$ and $\mathbf{3}$ in the series of macrolides, presents the same lower coefficient of division $(\log \mathrm{P})$. These molecules possess a good solubility. Compound 1 has important hydration energy. It has as a consequence a better distribution in fabrics.

\section{REFERENCES}

1. Z.Q. Ye, T.Y. Gao and G. Zhao, Tetrahedron, 67, 5979 (2011)

2. S. Ma, B. Jiao, Y.J. Ju, M.J. Zheng, R.X. Ma, L. Liu, L. Zhang, X.C. Shen, C.C. Ma, Y. Meng, H. Wang, Y.K. Qi, X.D. Ma and W.P. Cui, Eur. J. Med. Chem., 46, 556 (2011).

3. B.C. Raimundo and C.H. Heathcock, Org. Lett., 2, 27 (2000).

4. S. Omura, Macrolide Antibiotics Chemistry Biology and Practice, Academic press, New-york (1984).

5. K. Gustafson, M. Roman and W. Fenical, J. Am. Chem. Soc., 111, 7519 (1989).

6. T. Nagao, K. Adachi, M. Sakai, M. Nishijima and H. Sano, J. Antibiotics, 54, 333 (2001)

7. C. Jaruchoktaweechai, K. Suwanborirux, S. Tanasupawatt, P. Kittakoop and P.J. Menasveta, J. Nat. Prod., 63, 984 (2000).

8. H. Kim, W. Kim, I. Ryoo, C. Kim, J. Suk, K. Han, S. Hwang and I. Yoo, J. Microbiol. Biotechnol., 7, 434 (1997).

9. S.W. Choi, D.H. Bai, J.H. Yu and C.S. Shin, Can. J. Microbiol., 49, $663(2003)$

10. S. Carmely and Y. Kashman, Tetrahedron Lett., 26, 511 (1985).

11. M. Ojika, T. Nagoya and K. Yamada, Tetrahedron Lett., 36, 7491 (1995).

12. Y. Dong, J. Yang, H. Zhang, J. Lin, X. Ren, M. Liu, X. Lu and J. He, J. Nat. Prod., 69, 128 (2006).

13. W.C. Still and I. Galynker, Tetrahedron, 37, 3981 (1981).
14. D.M. Grée, C.J.M. Kermarrec, J.T. Martelli, R.L. Grée, J.P. Lellouche and L.J. Toupet, J. Org. Chem., 61, 1918 (1996).

15. R. Grée and J.P. Lellouche, Adv. Metal-Org. Chem., 4, 1 (1993).

16. S. Belaidi, M. Laabassi, R. Gree and A. Botrel, Sci. Study Res., 4, 27 (2003).

17. S. Belaidi, M. Laabassi, R. Gree and A. Botrel, Rev. Roum. Chim., 50, 759 (2005)

18. J. Koca, J. Mol. Struct., 291, 255 (1993).

19. N.L. Allinger, Pure Appl. Chem., 54, 2515 (1982).

20. N.L. Allinger, J. Am. Chem. Soc., 99, 8127 (1977).

2.1 N. Metropolis, A.W. Rosenbluth, M.N. Rosenbluth, A.H. Teller and E. Teller, J. Chem. Phys., 21, 1087 (1953).

22. HyperChem (Molecular Modeling System) Hypercube, Inc., 1115 NW, 4th Street, Gainesville, FL32601; USA (2006).

23. C.S. Chem3D Pro, Molecular Modelling and Analysis, Cambridge Soft Corporation, 875 Massachusetts, 02139c USA (2005).

24. S. Belaidi, M. Omari and A. Dibi, J. Soc. Algér. Chim., 10, 221 (2000).

25. S. Belaidi, A. Dibi and M. Omari, Turk. J. Chem., 26, 491 (2002).

26. S. Belaidi, M. Omari, T. Lanez and A. Dibi, J. Soc. Algér. Chim., 14, 27 (2004).

27. S. Belaidi, T. Lanez, M. Omari and A. Botrel, Asian J. Chem., 17, 859 (2005).

28. S. Belaidi and D. Harkati, ISRN Org. Chem., 2011, Article ID 594242 (2011).

29. M. Saunders, K.N. Houk, Y.-D. Wu, W.C. Still, M. Lipton and G. Chang, J. Am. Chem. Soc., 112, 1419 (1990).

30. T. Yamazaki, M. Ando, T. Kitazume, T. Kubota and M. Omura, Org. Lett., 1, 905 (1999).

31. L.R. Cox and S.V. Ley, Chem. Soc. Rev., 27, 301 (1998).

32. V.N. Viswanadhan, A.K. Ghose, G.R. Revankar and R.K. Robins, J. Chem. Informat. Comp. Sci., 29, 163 (1989).

33. A.K. Ghose and G.M. Crippen, J. Chem. Informat. Comp. Sci., 27, 21 (1987).

34. N. Bodor, Z. Gabanyi and C.K. Wong, J. Am. Chem. Soc., 111, 3783 (1989).

35. A. Gavezzotti, J. Am. Chem. Soc., 105, 5220 (1983).

36. K.J. Miller, J. Am. Chem. Soc., 112, 8533 (1990).

37. T. Ooi, M. Oobatake, G. Nemethy and H.A. Scheraga, Proc. Nat. Acad. Sci. (USA), 84, 3086 (1987).

38. E.H. Kerns and L. Di, Drug-like Properties: Concepts, Structure Design and Methods: from ADME to Toxicity Optimization, Elsevier Inc, pp. 43-47 (2008)

39. B. Yavorski and A. Detlaf, Checklist of Physics, Editions Mir, Moscow, p. $376(1980)$

40. TAMMO, 'Theoretical Analysis of Molecular Membrane Organization, CRC Press, Boca Raton, Florida, USA (1995).

41. M. Deleu, Ph.D. Thesis, Synthesis of Surfactin Derivatives and Study their Properties, FUSAGX, Belgium (2000).

42. L.B. Kier, Molecular Orbital Theory in Drug Research, Academic Press, New York, NY, USA (1981). 